\title{
Macrophage Activation Led Acute Heart Failure Managed Successfully with Immunosuppression
}

\author{
Karan Seegobin (D) \\ Muhamad Alhaj Moustafa (D) \\ Umair Majeed' \\ Jordan C Ray ${ }^{2}$ \\ Marwan Shaikh ${ }^{1}$ \\ Liuyan Jiang $\mathbb{B D}^{3}$ \\ Han W Tun (D) \\ 'Department of Hematology and Medical \\ Oncology, Mayo Clinic, Jacksonville, FL, \\ 32224, USA; '2Departmentof Cardio- \\ Oncology, Mayo Clinic, Jacksonville, FL, \\ 32224, USA; ${ }^{3}$ Department of Pathology, \\ Mayo Clinic, Jacksonville, FL, 32224, USA
}

Correspondence: Han W Tun Department of Hematology and Medical Oncology, Mayo Clinic Hospital, Jacksonville, FL, 32224, USA

Email Tun.Han@mayo.edu

\begin{abstract}
Macrophage activation leading to multi-organ dysfunction/failure has been described in various hematologic disorders like hemophagocytic lympho-histiocytosis (HLH), also known as macrophage activation syndrome (MAS) and macrophage activation like syndrome (MALS). Congestive heart failure (CHF) appears to be an uncommon manifestation of macrophage activation. This novel entity of macrophage activationassociated cytokine-mediated CHF has not been well reported in the medical literature. We report two young female patients with acute CHF secondary to macrophage activationassociated cytokine storm. An extensive diagnostic workup was negative for other etiologies, such as ischemia, myocarditis, or infections. Their clinical, laboratory, and pathologic findings did not meet the diagnostic criteria for hemophagocytic syndrome (HPS)/MAS. However, both had laboratory and pathologic findings which were consistent with macrophage activation and cytokine storm. One patient met criteria for MALS. Therapeutically, our patients were promptly treated with steroids with or without anti-cytokine therapy with rapid restoration of cardiac function. Macrophage activation-induced disease may not always fulfil the diagnostic criteria for the currently known macrophage activation disorders. We suggest that markers of macrophage activation and cytokine levels should be part of the diagnostic workup in patients with otherwise unexplained acute CHF. Additional research is warranted to further elucidate the underlying mechanism of this disorder.
\end{abstract}

Keywords: macrophage activation syndrome, MAS, macrophage activation like syndrome, MALS, cytokine release storm, CRS, reversible systolic heart failure, immunosuppression

\section{Plain Language Summary}

Macrophages are cells that surround and kill microorganisms, remove dead cells, and stimulate the action of other immune system cells. These macrophages are found in many organs and produce cytokines which is a chemical that can drive inflammation. In excess these cytokines can affect other organs such as the heart and result in heart failure. Some laboratory tests that can indicate macrophage activation include elevated ferritin, triglyceride, and CRP. Steroids and other anti-inflammatory medications can suppress this inflammation and improve symptoms and organ function in these patients with macrophage activation and organ dysfunction. We report two cases with unexplained heart failure who were found to have features of macrophage activation after further workup. They both responded promptly to immunosuppressive treatment. We suggest that markers of macrophage activation should be evaluated in patients with unexplained CHF. In some proven cases of heart failure, secondary to macrophage activation, prompt treatment with immunosuppressants could lead to clinical improvement, and such treatment should be sought only after other causes of heart failure have been clearly ruled out and must be done by physicians with expertise in managing heart failure. 


\section{Introduction}

Macrophage activation leading to multi-organ dysfunction/ failure has been described in various hematologic disorders including hemophagocytic lympho-histiocytosis (HLH)/ macrophage activation syndrome (MAS), and macrophage activation like syndrome (MALS). ${ }^{1,2}$ Congestive heart failure (CHF) appears to be an uncommon manifestation of macrophage activation. ${ }^{3}$ We found seven case reports of HLH presenting with systolic heart failure in the medical literature (Table 1), six of whom had complete recovery of cardiac function with immunosuppressive therapy; post treatment cardiac function was not reported in one case. Here we report two cases of acute CHF associated with laboratory and pathologic evidence of macrophage activation and cytokine storm without meeting the diagnostic criteria for MAS/HLH. One patient met the criteria for MALS. Both cases had increased M2 macrophages in the bone marrow. Both cases had a dramatic response to immunosuppressive therapy with full recovery of cardiac function.

\section{Case I}

A 37-year-old female without any prior co-morbidity was hospitalized with acute onset of severe shortness of breath and fatigue. The initial examination showed blood pressure 102/96 mmHg, pulse $121 \mathrm{bpm}$, temperature $36.8{ }^{\circ} \mathrm{C}$, respiratory rate $35 \mathrm{bpm}$ and $\mathrm{SpO} 294 \%$ on $2 \mathrm{LO} 2$. Bilateral inspiratory crackles were present on chest auscultation with normal heart sounds, S1 and S2, with added S3. Initial workup (Table 2) showed hemoglobin $9.3 \mathrm{~g} / \mathrm{dL}$ (11.6-15), hematocrit 54\% (35.5-44.9), platelet $76 \times 10^{9}$ (157-371), white cell count $2.4 \times 10^{9}$ (3.4-9.6), absolute neutrophil count $0.11 \times 10^{9}(1.56-6.45)$, absolute monocyte $3.0 \times 10^{9}(0.26-0.81)$, NT proBNP $17,280 \mathrm{pg} / \mathrm{mL}(<140)$, troponin $\mathrm{T} 11(<10 \mathrm{ng} / \mathrm{L})$, triglyceride $556 \mathrm{mg} / \mathrm{dL}(\mathrm{H})$, fibrinogen $312 \mathrm{mg} / \mathrm{dL}$ (200-393), ferritin 568 (11-307 $\mathrm{mcg} / \mathrm{L})$, CRP $92.4(<8.0 \mathrm{mg} / \mathrm{L}), \mathrm{LDH} 261$ (122-222 U/ L), presence of heterozygous prothrombin G20210A gene mutation, and interleukin-6, $8.6 \mathrm{pg} / \mathrm{mL}(<1.8)$, creatine kinase $80 \mathrm{U} / \mathrm{L}$ (26-192). Serial troponin T levels were 10 $\mathrm{ng} / \mathrm{L}$ (6 hours after), and $8 \mathrm{ng} / \mathrm{L}$ (on day 2). Her HScore was 98 points based on the above results. Other lab workup including renal function panel, liver function panel, and autoimmune screen were unremarkable. Blood smear showed absolute neutropenia with left-shifted neutrophils and markedly increased immature monocytes. Electrocardiogram (EKG) showed sinus tachycardia with $\mathrm{T}$ inversion in the inferior leads. CT chest showed moderate bilateral pleural effusions, interstitial edema and central perivascular ground-glass opacities. Echocardiogram showed ejection fraction of $25 \%$, with severe generalized left ventricular hypokinesis; normal left ventricular chamber size and thickness; normal right ventricular chamber size with reduced systolic function; right ventricle pressure $23 \mathrm{mmHg}$; right and left atrium was of normal size; mild

Table I Literature Review of Prior Cases with HLH Systolic Heart Failure

\begin{tabular}{|l|l|l|l|l|l|}
\hline Case & Age & Association & $\begin{array}{l}\text { Takotsubo } \\
\text { Features }\end{array}$ & Treatment & $\begin{array}{l}\text { Complete Recovery } \\
\text { of Cardiac Function } \\
\text { on Echo }\end{array}$ \\
\hline Zhou JY, et al $^{14}$ & $\begin{array}{l}45 \text {-year-old } \\
\text { female }\end{array}$ & Lamotrigine & Yes & Etoposide, dexamethasone & Yes \\
\hline Otillio JK, et al & 6-year-old female & Infection & Yes & $\begin{array}{l}\text { Etoposide, cyclosporine, and } \\
\text { dexamethasone }\end{array}$ & Yes \\
\hline Takeoka Y, et al & $\begin{array}{l}\text { 73-year-old (A) } \\
\text { and 56-year-old } \\
\text { female (B) }\end{array}$ & $\begin{array}{l}\text { EBV (A), T cell } \\
\text { lymphoma (B) }\end{array}$ & $\begin{array}{l}\text { Yes (A and } \\
\text { B) }\end{array}$ & $\begin{array}{l}\text { Etoposide, cyclosporine, and } \\
\text { dexamethasone (A); carboplatin, } \\
\text { cytarabine, dexamethasone (B) }\end{array}$ & Yes (A and B) \\
\hline Prakash PB, et al & $\begin{array}{l}\text { I-year old female } \\
\text { Infection }\end{array}$ & $\begin{array}{l}\text { No } \\
\text { (anakinra), methylprednisolone and } \\
\text { tacrolimus }\end{array}$ & Yes \\
\hline Abdin A ${ }^{17}$ & 59-year-old male & Unclear etiology & Yes & High-dose steroids & Yes \\
\hline Ullah W, et al ${ }^{18}$ & 32 -year-old male & Infection (HIV) & Yes & Dexamethasone, etoposide & Yes \\
\hline Chizinga M, et al & 32 -year-old male & $\begin{array}{l}\text { Systemic juvenile } \\
\text { idiopathic } \\
\text { arthritis (SJIA) }\end{array}$ & $\begin{array}{l}\text { No (right } \\
\text { sided heart } \\
\text { failure) }\end{array}$ & Dexamethasone, Anakinra. & $\begin{array}{l}\text { Not reported, patient } \\
\text { clinically improved }\end{array}$ \\
\hline
\end{tabular}


Table 2 Laboratory, Bone Marrow and ECHO Findings of Case I and 2

\begin{tabular}{|c|c|c|}
\hline & Case I & Case 2 \\
\hline \multicolumn{3}{|l|}{ Laboratory } \\
\hline $\mathrm{Hb}(1 \mathrm{I} .6-15)$ & $9.3 \mathrm{~g} / \mathrm{dL}$ & $7.9 \mathrm{~g} / \mathrm{dL}$ \\
\hline $\begin{array}{l}\text { WCC (3.4-9.6) } \\
\times 10^{9}\end{array}$ & $2.4 / \mathrm{L}$ & I.I /L \\
\hline Platelet (I57-37I) & $76 / L$ & $33 / L$ \\
\hline Triglyceride & $556 \mathrm{mg} / \mathrm{dL}$ & 970 mg/dL \\
\hline Ferritin (II-307) & $731 \mathrm{mcg} / \mathrm{L}$ & $5446 \mathrm{mcg} / \mathrm{L}$ \\
\hline LDH (I 22-222) & $261 \mathrm{U} / \mathrm{L}$ & $534 \mathrm{U} / \mathrm{L}$ \\
\hline $\begin{array}{l}\text { IL } 2 \text { receptor } \\
(C D 25)(\leq 1033)\end{array}$ & - & $1599 \mathrm{pg} / \mathrm{mL}$ \\
\hline CRP $(<8.0)$ & $92.4 \mathrm{mg} / \mathrm{L}$ & - \\
\hline IL-6 (<I.8) & $8.6 \mathrm{pg} / \mathrm{mL}$ & $10.2 \mathrm{pg} / \mathrm{mL}$ \\
\hline Bone Marrow & $\begin{array}{l}\text { Diffuse infiltration by } \\
\text { CD68+ macrophages }\end{array}$ & $\begin{array}{l}\text { Increased CD68 + } \\
\text { macrophages }\end{array}$ \\
\hline $\mathrm{ECHO}$ & $\begin{array}{l}\text { EF } 25 \% \text {, severe left } \\
\text { ventricular } \\
\text { hypokinesis }\end{array}$ & $\begin{array}{l}\text { EF } 21 \% \text {, global } \\
\text { decrease in systolic } \\
\text { function }\end{array}$ \\
\hline
\end{tabular}

mitral valve regurgitation, mild tricuspid valve regurgitation; normal aortic and pulmonary valve; small pericardial effusion (video 1). Abdominal ultrasound showed normal spleen and liver size. Initially she was started on broadspectrum antibiotics (vancomycin, piperacillin and tazobactam) and diuretics. Her oxygen requirements increased within 24 hours of admission necessitating non-invasive positive-pressure ventilation with BIPAP at $50 \% \mathrm{FiO}$, and ICU monitoring. She remained hemodynamically stable in the ICU and did not require inotropic support. After 72 hours, extensive workup for underlying infection including bacterial, viral, fungal and mycobacterial organisms were all negative; and despite antibiotics, interleukin6 and ferritin continued to increase to 11.4, and 731 respectively, with increasing liver enzymes. Bone marrow biopsy showed hypercellularity with diffuse infiltration by CD68+ macrophages and atypical megakaryocytes; the macrophages are predominantly type 2 macrophages since they are negative for pSTAT1 and positive for CD163 (Figure 1). Chromosome analysis, acute myeloid leukemia (AML) FISH panel, next generation sequencing (NGS) for myeloid neoplasms (11 gene panel), and myeloproliferative neoplasm (MPN) panel (JAK2, CALR,
MPL) were all negative. Macrophage activation associated cytokine-mediated disease process was suspected in the absence of evidence for ischemia, myocarditis, autoimmune disorders, and infections. She was treated with dexamethasone $40 \mathrm{mg}$ daily and had significant clinical improvement, no longer requiring oxygen after 5 days of steroids. Furthermore, echocardiogram after 5 days of steroids showed significant improvement in $\mathrm{EF}$ to $55 \%$ with normal left ventricular chamber size, wall thickness and regional wall motion; normal left ventricular diastolic function; normal right ventricular chamber size and function; estimated right ventricular systolic pressure 23 mmHg; mild mitral valve regurgitation and mild tricuspid valve regurgitation; normal pulmonary valve systolic velocity and small circumferential pericardial effusion (video 2). There was also resolution of hematologic abnormalities.

She was discharged on a 6-week steroid taper. One month later, ejection fraction was $62 \%$ and at 2-month follow-up she was clinically doing well. Unfortunately, several months later she was found to have avascular necrosis of the bilateral distal femur and proximal tibia and is currently followed by orthopedics for further care. She was started on Eliquis $10 \mathrm{mg}$ twice daily for 7 days then $5 \mathrm{mg}$ twice daily for 21 days, then $2.5 \mathrm{mg}$ twice daily for 6 months in light of the possible association of her prothrombin gene mutation and development of avascular necrosis. Her pain symptom subjectively improved with the initiation of anticoagulation.

\section{Case 2}

A 41-year-old female was hospitalized with subjective fever, nausea, vomiting, and abdominal pain which were present for 3 weeks. Initial examination showed blood pressure $66 / 39 \mathrm{mmHg}$, pulse $135 \mathrm{bpm}$, temperature 36.6 ${ }^{\circ} \mathrm{C}$, respiratory rate $35 \mathrm{bpm}$ and $\mathrm{SpO} 299 \%$. Normal heart sounds and breath sounds were heard on auscultation. Initial workup (Table 2) showed hemoglobin $7.9 \mathrm{~g} / \mathrm{dL}$ (11.6-15), hematocrit $24.7 \%(35.5-44.9)$, platelet $33 \times 10^{9}$ (157-371), white cell count $1.1 \times 10^{9}$ (3.4-9.6), absolute neutrophil count $0.5 \times 10^{9}(1.56-6.45)$, troponin T $17(<10$ $\mathrm{ng} / \mathrm{L}$ ), triglyceride $970 \mathrm{mg} / \mathrm{dL}$, fibrinogen $601 \mathrm{mg} / \mathrm{dL}$ (200-393), ferritin 5446 (11-307 mcg/L), LDH 534 (122-222 U/L), interleukin 2 receptor (CD25) soluble $1599 \mathrm{pg} / \mathrm{mL}$ ( $\leq 1033)$, IL-6 $10.2 \mathrm{pg} / \mathrm{mL}$, prothrombin time $14.4(9.4-12.5 \mathrm{sec})$, INR $1.3(0.9-1.1)$, activated partial prothrombin time $35(25-37 \mathrm{sec})$ and elevation of liver enzymes (total bilirubin $3.1 \mathrm{mg} / \mathrm{dL}(<1.2)$, direct bilirubin 


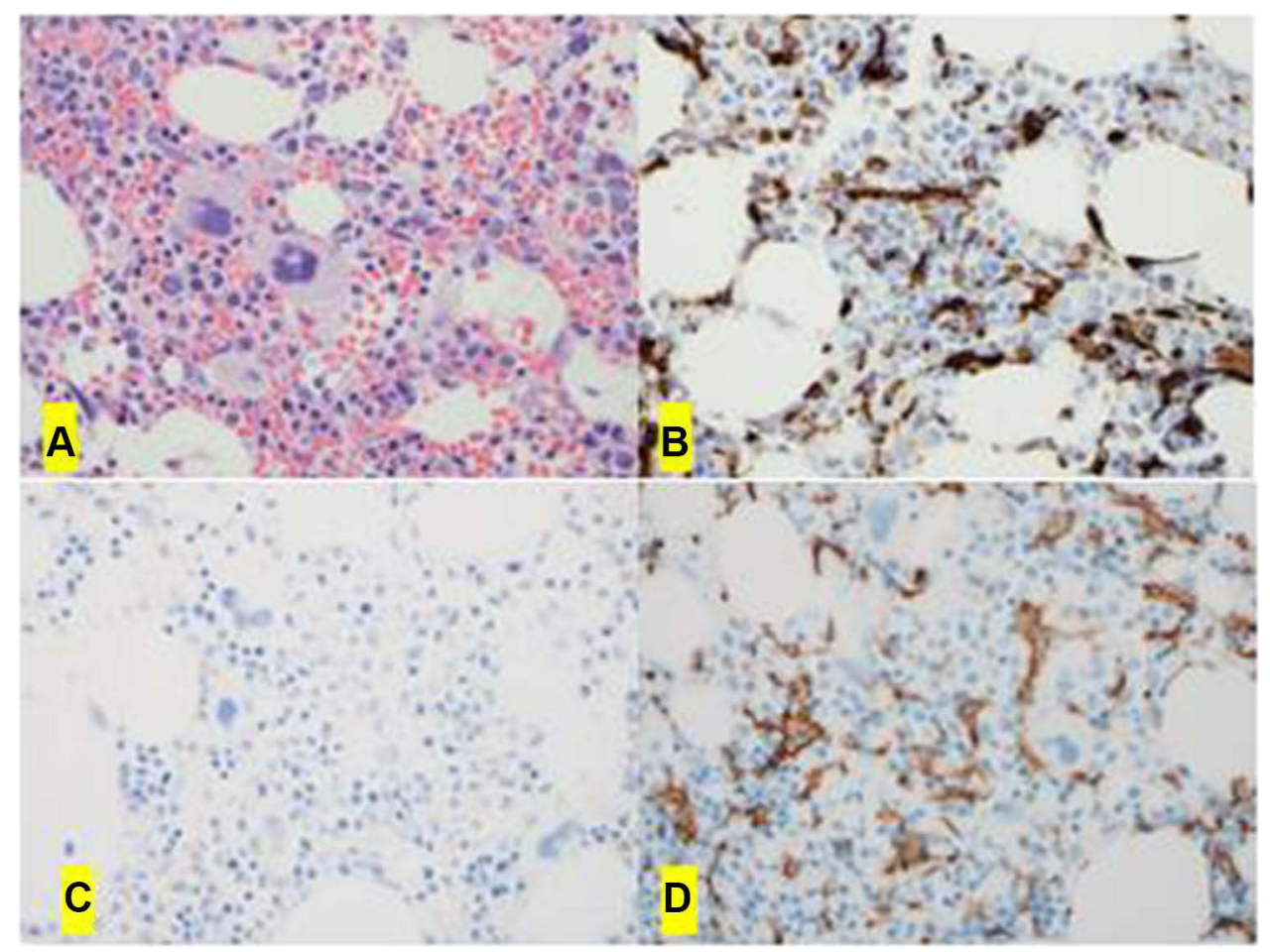

Figure I The bone marrow biopsy shows hypercellularity with increased megakaryocytes (A, H\&E x40). The immunohistochemical studies show increased interstitial macrophages by CD68 (PGMI) (B, x40); and they are type 2 macrophages negative for PSTATI (C, x 0) but positive for CDI63 (D, x40).

$2.7 \mathrm{mg} / \mathrm{dL}(0-0.3)$, alanine aminotransferase $81 \mathrm{U} / \mathrm{L}(7-$ 45), aspartate aminotransferase $241 \mathrm{U} / \mathrm{L}(8-43)$, alkaline phosphatase $117 \mathrm{U} / \mathrm{L}$ (35-104). Serial troponin T levels were $13 \mathrm{ng} / \mathrm{L}$ (day 2) and $18 \mathrm{ng} / \mathrm{L}$ D3 (day 3). Other laboratory workup included renal function panel and autoimmune screen were unremarkable. Her HScore was 152 based on the above results. Blood smear showed absolute leukopenia and lymphopenia. EKG showed sinus tachycardia with $\mathrm{T}$ inversions in $\mathrm{V} 1$.

Echocardiogram showed left ventricular ejection fraction $21 \%$ with a normal size and thickness left ventricle with multiple regional wall motion abnormalities in non -coronary distribution and associated global decrease in systolic function; grade 3/4 left ventricular diastolic dysfunction, consistent with severely elevated left ventricular filling pressure; normal right ventricular chamber size with mild global decrease in systolic function, right ventricular systolic pressure $42 \mathrm{mmHg}$, tricuspid annular plane systolic excursion (TAPSE) was $11 \mathrm{~mm}(20-22)$; mitral valve was normal with moderate mitral valve regurgitation and severe tricuspid valve regurgitation. Aortic and pulmonary valves were normal. No pericardial effusion. Normal size of both right and left atrium (video 3). Abdominal ultrasound did not show splenomegaly/hepatomegaly. She was started on broad spectrum antibiotics (vancomycin, piperacillin and tazobactam) and admitted to ICU as she required inotropic support with milrinone starting at $0.375 \mathrm{mcg} / \mathrm{kg} / \mathrm{min}$ and then titrated as needed to maintain blood pressure. Extensive workup for underlying infection including bacterial, viral, fungal and mycobacterial organisms were all negative. Bone marrow biopsy showed hypocellularity with left-shifted myelopoiesis, increased clusters of immature myeloid precursors, and increased CD68+ macrophages, which were predominantly type 2 macrophages negative for pSTAT1 and positive CD163 (Figure 2). Chromosome analysis, AML FISH, NGS for myeloid neoplasms (11 gene panel), MPN panel (JAK2, CALR, and MPL), immunoglobulin gene rearrangement, and T-cell receptor gene rearrangements were all unremarkable. Macrophage activation associated cytokinemediated systemic disease process was suspected and treated with anakinra (anti-IL1) $100 \mathrm{mg}$ subcutaneous for 7 days, and dexamethasone $10 \mathrm{mg}$ once daily for 7 days followed by a 6-week steroid taper. She clinically improved rapidly and was completely off inotropic support after 6 days of immunosuppression treatment. Repeat echocardiogram after 7 days of immunosuppressive treatment showed significantly improved left ventricular 


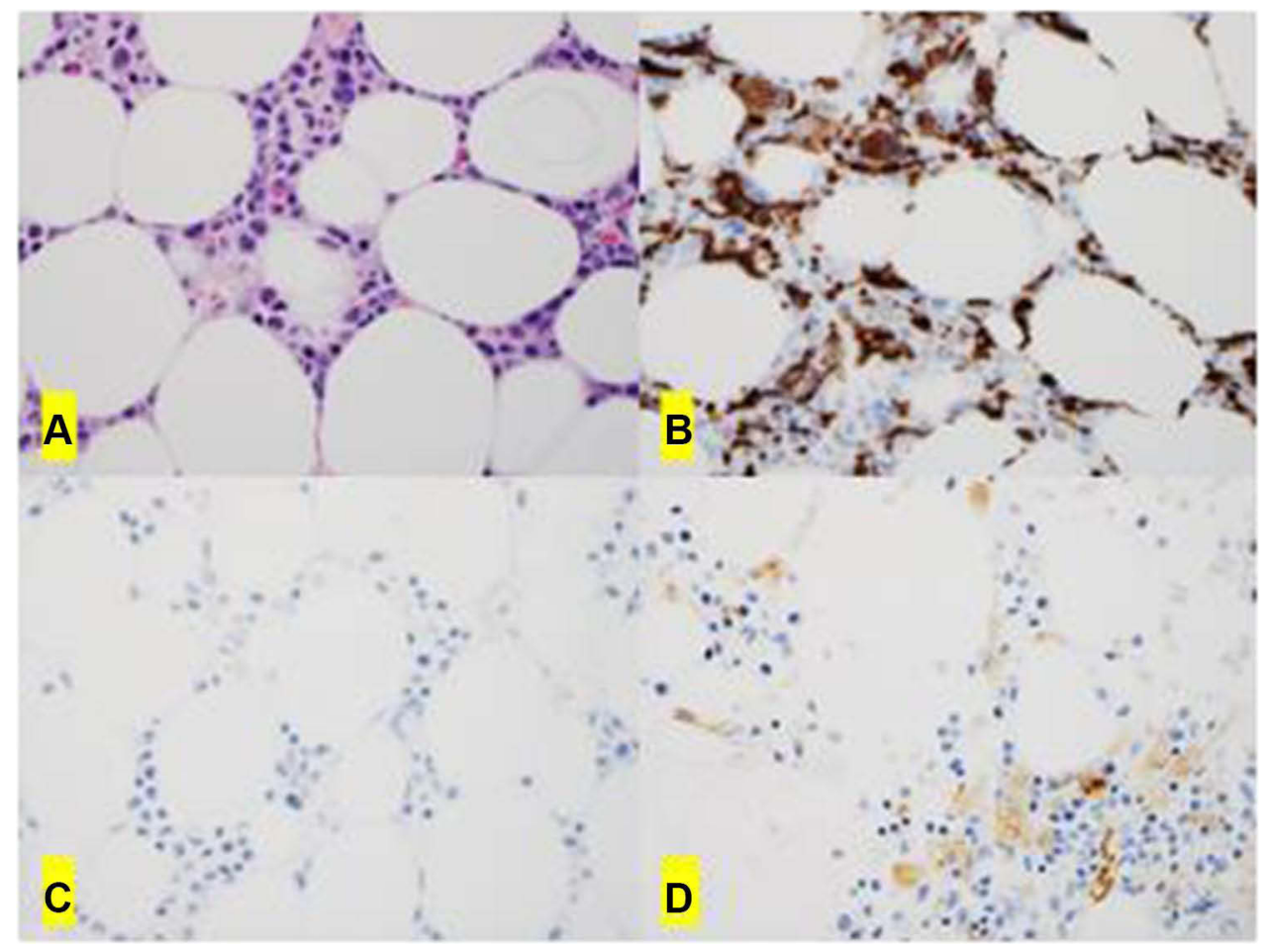

Figure 2 The bone marrow biopsy shows hypocellularity with left-shifted myelopoiesis $(\mathbf{A}, \mathrm{H} \& \mathrm{E} \times 0)$. Immunohistochemical studies shows increased interstitial macrophages by CD68 (PGMI) (B, x40); they are type 2 macrophages (M2) negative for PSTATI (C, $x$ 0) and positive for CDI63 (D, x40).

function with ejection fraction $70 \%$; normal left ventricular chamber size and wall thickness with hyperdynamic systolic function; normal right ventricular chamber size and function; no regional wall motion abnormalities; no pericardial effusion (video 4). Complete resolution of cytopenias and normalization of liver function was also seen. At 8 months follow up she has no clinical features of heart failure.

\section{Discussion}

Our two young patients represent unique cases of acute CHF secondary to macrophage activation-associated cytokine storm with one patient meeting criteria for MALS. It is interesting that they did not meet the diagnostic criteria for known macrophage activation disorders such as HLH, also known as MAS. ${ }^{2,4,5}$ They clearly had laboratory evidence of macrophage activation which includes elevated ferritin, triglyceride, CRP, IL- 6 , and CD25. ${ }^{2}$ The other prominent finding is infiltration of the bone marrow by CD68+ type 2 macrophages, associated with pancytopenia which can be seen in HLH/MAS. ${ }^{2}$ It appears that activated macrophages are located in the bone marrow compromising hematopoiesis and mediating CHF via cytokine storms. In our cases the underlying mechanism for macrophage activation is not clear, negative extensive genetic and molecular testing together with rapid response to immune suppression would indicate a reactive process inciting macrophage activation. They both had increased M2 macrophages in the bone marrow. M2 macrophages which can be seen in MAS, are heterogeneous in comparison to M1 macrophages. ${ }^{6}$ In these cells the production of proinflammatory mediators are downregulated. ${ }^{6}$ While they are mostly described as antiinflammatory, there is some data to suggest they may act as an innate immune sensor for bacteria and trigger production of pro-inflammatory cytokines. ${ }^{6,7}$

HLH/MAS is diagnosed if at least five of the eight criteria of the International Histiocyte Society (2004HLH criteria), published in 2007, are met: (a) fever, (b) splenomegaly, (c) cytopenia of at least two lineages; (d) fasting triglycerides $\geq 265 \mathrm{mg} / \mathrm{dl}$ and fibrinogen $\leq 150 \mathrm{mg} /$ $\mathrm{dl}$; (e) hemophagocytosis in the bone marrow; (f) low or absent NK-cell activity; (g) ferritin $\geq 500 \mathrm{ng} / \mathrm{mL}$; and soluble CD25 $\geq 2400$ units $/ \mathrm{mL}^{2}$ Presence of bone marrow hemophagocytosis is one of the criteria taken into consideration for the diagnosis of MAS. ${ }^{8}$ MALS, which is often described in the setting of sepsis, came about due to the difficulty of performing a bone marrow biopsy in every 
critically ill patient and is defined as an HS score more than 151 or patients with both hepatobiliary dysfunction (HBD) and disseminated intravascular coagulation (DIC). Both cases did not meet the criteria for HLH/MAS (they both had two out of the five criteria for HLH/MAS). We did not have NK cell activity or soluble CD 25 levels available in both cases. An HS score of case 2 met the criteria for MALS, further supporting the presence of macrophage activation. Our second case had more evidence of multiorgan dysfunction characterized by liver dysfunction, heart failure and lower degrees of cytopenias (with respect to case 1) and overall was more critically ill and required inotropic support. It is possible that she may have been on the more severe end of the disease spectrum of macrophage activating disorders; while our first patient who did not have liver dysfunction, less severe cytopenias and not requiring inotropic support may have been on a milder end of the spectrum characterizing this novel entity of macrophage activation-associated cytokinemediated CHF. Bone marrow features of macrophage activation were present in both cases. One hypothesis is that macrophage activation in the bone marrow may be the first sign of the disease and if not diagnosed early may propagate from macrophage associated cytokine storm to the more severe end of the spectrum (manifesting as MALS or $\mathrm{HLH}$ ) with HLH being the most severe of these entities.

The other unique aspect of our two patients is CHF as a prominent organ dysfunction. In our medical literature search, we identified only seven case reports of HLH with systolic heart failure (Table 1). Of note right ventricle failure without involvement of the left ventricle can also be involved. ${ }^{9}$ It appears that CHF is uncommon in macrophage activation disorders. ${ }^{3}$ In those cases and our two patients, immunosuppressive therapy worked very well with rapid restoration of cardiac function. The ECHO findings in both cases and non-rising troponin levels helped rule out other conditions such as takotsubo cardiomyopathy, myocarditis and acute myocardial infarction. Cardiac catheterization was not pursued considering their quick recovery with immunosuppressive medications.

We used steroid monotherapy in our first patient and steroid with anakinra (Anti-IL-1 monoclonal antibody) in our second patient with excellent therapeutic outcomes. Dexamethasone is a standard steroid used in management of HLH. ${ }^{10}$ We chose to use anakinra in our second patient as her clinical status was rapidly deteriorating. IL-1 is an important cytokine which can activate an innate immune response with activation of macrophages. ${ }^{11}$ In both patients, IL-6 was elevated. It would have also been reasonable to try anti-IL-6 monoclonal antibody therapy. In some cases while patients respond to immunosuppressive medications additional supportive care, such as venoarterial extracorporeal membrane oxygenation (VAECMO), may be needed and can be lifesaving. ${ }^{9}$

Unfortunately, our first patient developed avascular necrosis several months after she recovered from her episode of heart failure. There are many short-term and long-term side effects of high dose steroids, avascular necrosis is one such reported side effect. We felt other factors may have contributed to her avascular necrosis, such as the presence of her prothrombin G20210A gene mutation. Hypercoagulable states have been reported to be associated with avascular necrosis and anticoagulation has been reported to help in some cases. This was our rationale using Eliquis in this patient. $^{12,13}$ It is unclear if macrophage activation would have had a role in the pathogenesis of her avascular necrosis. Monitoring for adverse effects of steroids during the shortand long-term follow up of these patients is also important.

In conclusion, we report a novel macrophage activationinduced disease entity which does not fulfil the diagnostic criteria for HLH/MAS and is clinically characterized prominently by acute CHF and pancytopenia. We suggest that macrophage activation should be entertained as a differential diagnosis in patients with acute, otherwise unexplained, CHF. Markers of macrophage activation and hematologic parameters including complete blood counts and bone marrow biopsy should be evaluated to diagnose this entity. Therapeutically, patients with this disorder should be promptly treated with steroids and anti-cytokine therapy after considering the risk of the therapy vs benefit and only patients with proven cases should be treated with immunosuppressants. The clinical outcome could be better if the disease is recognized early in the course and appropriate therapy, such as immunosuppressants, started early with consideration of advanced therapies such as ECMO in refractory cases. Additional research is warranted to further elucidate the underlying disease mechanism.

\section{Ethics Approval}

Institutional approval was not required to publish the case details.

\section{Consent}

Written and informed consent was obtained from both patients for publication of this manuscript. 


\section{Acknowledgments}

We thank the patients for providing consent to publish this article.

\section{Author Contributions}

All authors made a significant contribution to the work reported, whether that is in the conception, study design, execution, acquisition of data, analysis and interpretation, or in all these areas; took part in drafting, revising or critically reviewing the article; gave final approval of the version to be published; have agreed on the journal to which the article has been submitted; and agree to be accountable for all aspects of the work.

\section{Funding}

There is no funding to report.

\section{Disclosure}

All authors have no conflicts of interest to declare.

\section{References}

1. Bracaglia C, Prencipe G, De Benedetti F. Macrophage activation syndrome: different mechanisms leading to a one clinical syndrome. Pediatr Rheumatol Online J. 2017;15(1):5. doi:10.1186/s12969-0160130-4

2. Karakike E, Giamarellos-Bourboulis EJ. Macrophage activation-like syndrome: a distinct entity leading to early death in sepsis. Front Immunol. 2019;10:55. doi:10.3389/fimmu.2019.00055

3. Prakash PB, Raj S. Cytokine induced myocardial dysfunction in a patient with hemophagocytic lymphohistiocytosis. $\mathrm{J} \mathrm{Am}$ Coll Cardiol. 2016;67(13_Supplement):1061. doi:10.1016/S0735-1097(16) 31062-2

4. Ravelli A, Minoia F, Davi S, et al. Classification criteria for macrophage activation syndrome complicating systemic juvenile idiopathic arthritis: a European League Against Rheumatism/American College of Rheumatology/Paediatric Rheumatology International Trials Organisation Collaborative Initiative. Ann Rheum Dis. 2016;75 (3):481-489. doi:10.1136/annrheumdis-2015-208982

5. Henter JI, Horne A, Arico M, et al. HLH-2004: diagnostic and therapeutic guidelines for hemophagocytic lymphohistiocytosis. Pediatr Blood Cancer. 2007;48(2):124-131. doi:10.1002/pbc.21039
6. Grom AA, Mellins ED. Macrophage activation syndrome: advances towards understanding pathogenesis. Curr Opin Rheumatol. 2010;22 (5):561-566. doi:10.1097/01.bor.0000381996.69261.71

7. Röszer T. Understanding the mysterious $\mathrm{m} 2$ macrophage through activation markers and effector mechanisms. Mediators Inflamm. 2015;2015:816460. doi:10.1155/2015/816460

8. Kyriazopoulou E, Leventogiannis K, Norrby-Teglund A, et al. Macrophage activation-like syndrome: an immunological entity associated with rapid progression to death in sepsis. BMC Med. 2017;15 (1):172. doi:10.1186/s12916-017-0930-5

9. Chizinga M, Kalra SS, Innabi A, Rackauskas M, Ataya A, Emtiazjoo A. Macrophage activating syndrome causing decompensated right heart failure. Respir Med Case Rep. 2021;33:101409. doi:10.1016/j.rmcr.2021.101409

10. Lerkvaleekul B, Vilaiyuk S. Macrophage activation syndrome: early diagnosis is key. Open Access Rheumatol. 2018;10:117-128. doi:10.2147/OARRR.S151013

11. Mehta P, Cron RQ, Hartwell J, Manson JJ, Tattersall RS. Silencing the cytokine storm: the use of intravenous anakinra in haemophagocytic lymphohistiocytosis or macrophage activation syndrome. Lancet Rheumatol. 2020;2(6):e358-e67. doi:10.1016/S26659913(20)30096-5

12. Björkman A, Burtscher IM, Svensson PJ, Hillarp A, Besjakov J, Benoni G. Factor V Leiden and the prothrombin 20210A gene mutation and osteonecrosis of the knee. Arch Orthop Trauma Surg. 2005;125(1):51-55. doi:10.1007/s00402-004-0760-8

13. Björkman A, Svensson PJ, Hillarp A, Burtscher IM, Rünow A, Benoni G. Factor V Leiden and prothrombin gene mutation: risk factors for osteonecrosis of the femoral head in adults. Clin Orthop Relat Res. 2004;425:168-172. doi:10.1097/00003086-20040800000023

14. Zhou JY, Martinez JA, Shen JP. Lamotrigine-induced hemophagocytic lymphohistiocytosis with Takotsubo cardiomyopathy: a case report. Journal of Medical Case Reports. 2019;13(1):345.

15. Otillio JK, Harris JK, Tuuri R. A 6-year-old girl with undiagnosed hemophagocytic lymphohistiocytosis and takotsubo cardiomyopathy: a case report and review of the literature. Pediatr Emerg Care. 2014;30(8):561-565.

16. Takeoka Y, Nakamae M, Nakamae H, et al. Two cases of ampulla (takotsubo-shaped) cardiomyopathy associated with hemophagocytic lymphohistiocytosis. Acta Haematol. 2007;117(4):205-210.

17. Abdin A. Takotsubo Cardiomyopathy Due to Hemophagocytic Lymphohistiocytosis. CHEST. 2016;150(4):435A.

18. Ullah W, Hamid M, Grover H, Figueredo VM, Inayat F. Takotsubo cardiomyopathy secondary to haemophagocytic lymphohistiocytosis in HIV patients: a comprehensive review. BMJ Case Rep. 2019;12(4).

\section{Publish your work in this journal}

The Journal of Blood Medicine is an international, peer-reviewed open access, online journal publishing laboratory, experimental and clinical aspects of all aspect pertaining to blood based medicine including but not limited to: Transfusion Medicine; Blood collection, Donor issues, Transmittable diseases, and Blood banking logistics; Immunohematology; Artificial and alternative blood based therapeutics; Hematology; Biotechnology/nanotechnology of blood related medicine; Legal aspects of blood medicine; Historical perspectives. The manuscript management system is completely online and includes a very quick and fair peer-review system. Visit http://www.dovepress.com/testimonials.php to read real quotes from published authors. 